\title{
Predicting long-term response to strong opioids in patients with low back pain: findings from a randomized, controlled trial of transdermal fentanyl and morphine
}

\author{
Eija Kalso', Karen H Simpson ${ }^{2}$, Robert Slappendel ${ }^{3}$, Joachim Dejonckheere ${ }^{4}$ \\ and Ute Richarz*5
}

\begin{abstract}
Address: ${ }^{1}$ Pain Clinic, Helsinki University Central Hospital, Helsinki, Finland, ${ }^{2}$ Leeds Teaching Hospitals, Leeds, UK, ${ }^{3}$ Sint Maartenskliniek, Nijmegen, The Netherlands, ${ }^{4}$ SGS, Mechelen, Belgium and ${ }^{5} J a n s s e n-C i l a g$, Baar, Switzerland

Email: Eija Kalso - eija.kalso@hus.fi; Karen H Simpson - karen.simpson@dsl.pipex.com; Robert Slappendel - robslappendel@hotmail.com; Joachim Dejonckheere - joachim.dejonckheere@sgs.com; Ute Richarz* - urichar1@jacch.jnj.com

* Corresponding author
\end{abstract}

Published: 21 December 2007

BMC Medicine 2007, 5:39 doi:10.1/86/1741-7015-5-39
Received: 29 March 2007

Accepted: 21 December 2007

This article is available from: http://www.biomedcentral.com/I74I-70I5/5/39

(c) 2007 Kalso et al; licensee BioMed Central Ltd.

This is an Open Access article distributed under the terms of the Creative Commons Attribution License (http://creativecommons.org/licenses/by/2.0), which permits unrestricted use, distribution, and reproduction in any medium, provided the original work is properly cited.

\begin{abstract}
Background: Some patients with long-standing low back pain will benefit from treatment with strong opioids. However, it would be helpful to predict which patients will have a good response. A fixed-term opioid trial has been recommended, but there is little evidence to suggest how long this trial should be. We assessed data from a large-scale randomized comparison of transdermal fentanyl (TDF) and sustained-release oral morphine (slow-release morphine; SRM) to determine characteristics of treatment responders.
\end{abstract}

Methods: This was a secondary analysis of a previously published 13-month randomized trial involving 680 patients with long-standing low back pain (median age 52 years, $61 \%$ women, median duration of back pain 87 months). Pain relief was recorded using visual analogue scales (VAS). Treatment response was defined as pain relief of at least $30 \%$ from baseline to any point during the trial. We used a step-wise logistic regression to identify variables that might predict response to treatment. Covariates included treatment group, sex, age, duration of pain, presence of neuropathic pain, baseline pain scores, educational/employment status, use of high doses of opioids, and social functioning (SF)-36 scores.

Results: Over half the patients in both groups ( $n=370 ; 54 \%$ TDF, 55\% SRM) were treatment responders. There were no differences between the TDF and SRM responders in terms of age, sex, type or duration of pain between responders and non-responders. The difference in response to treatment between responders and non-responders could be detected at 3 weeks. Lack of response after I month had a stronger negative predictive value (i.e., ability to detect nonresponders) than the presence of response after I month. The most influential factors for predicting a response were employment status $\left(\chi^{2}=11.06, p=0.0259\right)$ and use of high doses of opioids $\left(\chi^{2}=3.04, p=0.08 \mathrm{I} I\right)$.

Conclusion: No clear pattern of baseline pain (type or severity) or patient characteristics emerged that could be used to predict responders before the start of opioid treatment. However, a I-month trial period appears sufficient to determine response and tolerability in most cases. 


\section{Background}

Strong opioids are accepted as an option for patients with long-standing low back pain, but not all patients respond satisfactorily to this treatment. It would be helpful to be able to predict which patients are most likely to have a good, long-term response to strong opioid therapy to avoid exposing patients to ineffective treatments or sideeffects. Even if it does not prove possible to identify good responders before starting treatment, it would be useful to know how long an opioid trial is required to determine response. We have analyzed findings from a randomized, controlled trial of transdermal fentanyl and sustainedrelease oral morphine in strong-opioid naive patients with chronic low back pain to gather information about predicting response and about the inter-relationships between analgesia and other effects of treatment.

\section{Methods}

The primary study (FEN-INT-26) has been published separately [1]. It included 680 patients with long-standing low back pain who were randomized to treatment with either slow-release morphine (SRM) or transdermal fentanyl (TDF) for 13 months. Individuals who had received regular treatment with a strong opioid (i.e. more than four doses over a 7 -day period) at any time during the 4 weeks preceding the study were excluded.

Patients were excluded if they had conditions that were likely to predispose them to ventilatory depression, intolerance to morphine or fentanyl (e.g. chest disease, renal dysfunction), skin problems that might affect transdermal delivery), a history of alcohol or substance abuse, or a lifelimiting condition.

Pain relief was assessed weekly using visual analogue scales for pain relief (VAS) from patient diaries. There were monthly assessments of pain (at rest, on movement, during the day and at night). Adverse events were recorded throughout the study. For the purpose of this secondary analysis, treatment response was defined as pain relief of at least $30 \%$ from baseline to any point during the trial [2].

We performed a step-wise logistic regression to identify variables that might predict response to treatment with strong opioids during the trial. Covariates included in the initial model were: randomization group (fentanyl or morphine), sex, age, duration of pain, presence of neuropathic pain, educational/employment status, use of high doses of opioids ( $>100 \mu \mathrm{g} / \mathrm{h}$ TDF or $>390 \mathrm{mg} /$ day SRM) during the trial, baseline scores for pain at rest, pain on movement, and SF-36 scores (mental health, social functioning and physical functioning). The selection of covariates focused on those, which might have a possible effect on treatment outcome based on published literature and clinical experience [3-12]. We examined the effects of these variables on the likelihood of patients experiencing at least a $30 \%$ or $50 \%$ pain relief at several time points. Responses at earlier time points ( 1 month) were analyzed as predictors for response later on.

\section{Patient characteristics}

The median age was 52 years (range 20-89), 61\% of the 680 participants were women. The median duration of back pain was 87 months (range 2-768, mean 125 months); $51 \%$ of patients completed the study. Reasons for withdrawal included adverse events (37\% TDF, 31\% SRM) and insufficient response (5\% TDF, 4\% SRM).

\section{Results \\ Responder analysis}

Treatment response was defined as a pain relief of at least $30 \%$ (VAS scores) at any time point during the trial. Over half the patients in both groups $(n=370 ; 54 \%$ for TDF, $55 \%$ for SRM) were classified as treatment responders. There were no differences between the TDF and SRM responders in age, sex, type of pain (nociceptive or neuropathic) or duration of pain between responders and nonresponders. The physical functioning score of the SF-36 differed only slightly between responders $(28,3)$ and non-responders $(30,1)$.

Of the participants who experienced at least a 30\% pain relief at any time during the trial, most (74\% for TDF and $70 \%$ for SRM) also experienced at least a $50 \%$ reduction in pain severity in one of the back pain categories. There was no difference between the 50\% responders and nonresponders in baseline characteristics.

The difference in response to treatment between responders and non-responders could be detected at 3 weeks. Both groups had similar pain severity after 1 week, but by 3 weeks the non-responders had, on average, more pain than at baseline, while the responders had less pain. This suggests that an assessment period of 1 month may be sufficient to determine responsiveness to a strong opioid.

The amount of patients suffering from moderate to severe pain in any of the low back pain categories was lower in the responder group at endpoint compared to the nonresponder group (Figure 1 ). There was however also a small reduction of patients suffering from moderate to severe pain in any of the low back pain categories in the non-responder group compared to baseline.

The odds ratios for the likelihood of being classified as a responder at 6 and 12 months (depending on whether patients were responders at 1 month) are shown in Table 1 . These indicate that a lack of response after 1 month has a stronger negative predictive value (i.e. ability to detect 


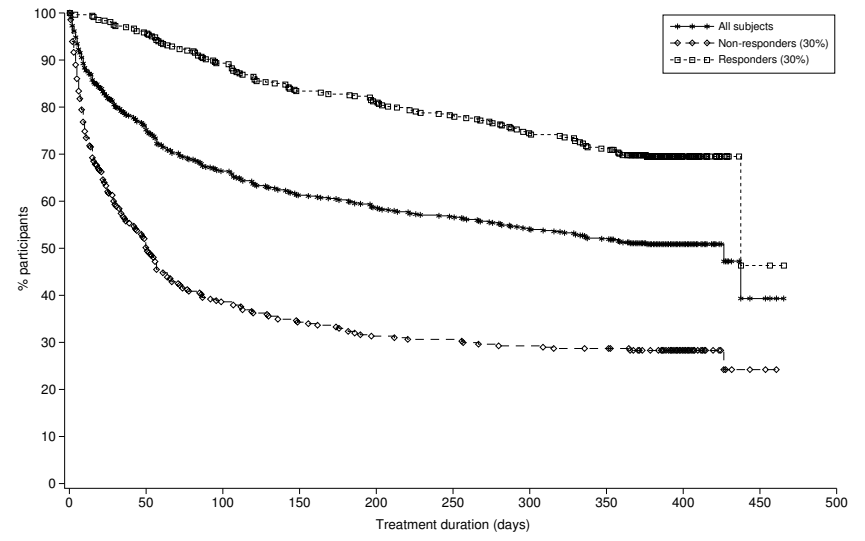

Figure I

Treatment duration in responders and non-responders.

non-responders) than the presence of response after 1 month. The predictive value for $50 \%$ pain relief was slightly higher than for $30 \%$ pain relief (odds ratios 5.08 and 4.36, respectively), but both were significantly associated with response at 6 months $(\mathrm{p}<0.0001$ in both cases). Response at 1 month was also associated with response at 12 months, although the odds ratios were less pronounced at this stage, probably due to the larger number of missing cases (OR 3.17 (95\% CI 1.77-5.68) for $30 \%$ response and $3.47(1.30-9.28)$ for $50 \%$ response).

Treatment responders were more likely to complete the study than non-responders $(69 \%$ for $30 \%$ responders vs $28 \%$ for non-responders). The most common reason for non-completion was an adverse event. On average, the non-responders dropped out of the study significantly earlier than the treatment responders ( 54 days vs 178 days $\mathrm{p}<0.001$, Figure 2). The rate of dropout for non-responders appeared to be greatest during the first 2 months, after which it reduced.
The dose pattern from 4 weeks to endpoint was broadly similar for $30 \%$ responders and non-responders who completed the study. The most common category of dose change over this period was $75-100 \%$; this was observed in $32 \%$ of responders and $35 \%$ of non-responders who completed the study. The proportion of patients whose opioid dose more than doubled between 4 weeks and study end (for those who completed the study) was identical for responders and non-responders $(24 \%$ in both groups).

\section{Characteristics of non-responders}

About half the participants were classified as treatment responders (i.e. had at least a 30\% pain relief VAS AUC [Area under the curve]); over three-quarters of participants $(530 / 680=78 \%)$ experienced some improvement in mental health, physical or social functioning (assessed by the SF-36) or an improvement in one of the specific back pain categories (at rest, during the day, at night, or on movement). Patients who had no response in any aspect tended to withdraw from the study after a short period (median time to withdrawal was 15 days for nonresponders vs 99 days for others, mean 34 and 139 days, respectively, $\mathrm{p}<0.001)$. Only $10(7 \%)$ of these nonresponders completed the study. The commonest reason for withdrawal was an adverse event that occurred in 111/ $136(82 \%)$ of the dropouts.

The small group of non-responders who remained in the study for more than 4 weeks $(n=37)$ tended to be on higher opioid doses than other patients. The mean dose (mg morphine or equivalents for fentanyl) at 5 weeks was 116 (95\% CI 92, 139) mg for non-responders compared with $94(89,98) \mathrm{mg}$ for other participants. At 12 weeks, the mean doses were 156 (95\% CI 104, 207) mg and 114 $(95 \%$ CI 107, 120) $\mathrm{mg}$, respectively.

Some aspects of pain improved more than others with strong-opioid treatment, e.g. the responders reporting

Table I: Relationship between pain relief at I month and at 6 months

\begin{tabular}{|c|c|c|c|c|}
\hline \multirow[t]{2}{*}{ Response at I month } & \multicolumn{3}{|c|}{ Response at 6 months $n(\%)$} & \multirow[t]{2}{*}{ Odds ratio $(95 \% \mathrm{Cl})$} \\
\hline & No & Yes & Missing & \\
\hline \multicolumn{5}{|l|}{ 30\% Response } \\
\hline No & $188(55)$ & $49(14)$ & 105 & $4.36(2.61-7.28)$ \\
\hline Yes & $44(35)$ & $50(40)$ & 30 & \\
\hline \multicolumn{5}{|l|}{ 50\% Response } \\
\hline No & $261(62)$ & $36(9)$ & 105 & $5.08(2.36-10.93)$ \\
\hline Yes & I4 (29) & $20(42)$ & 14 & \\
\hline
\end{tabular}


a

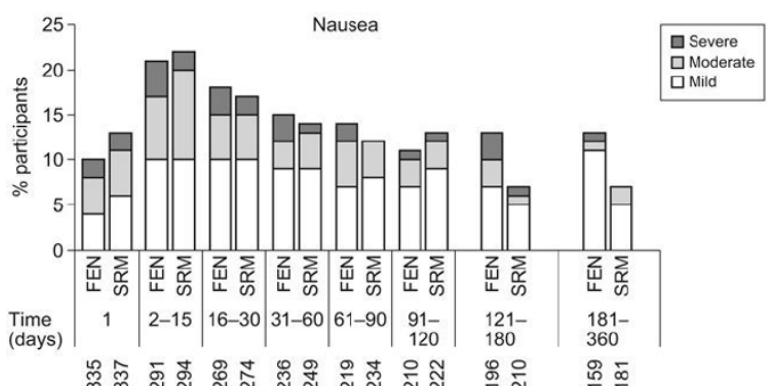

b
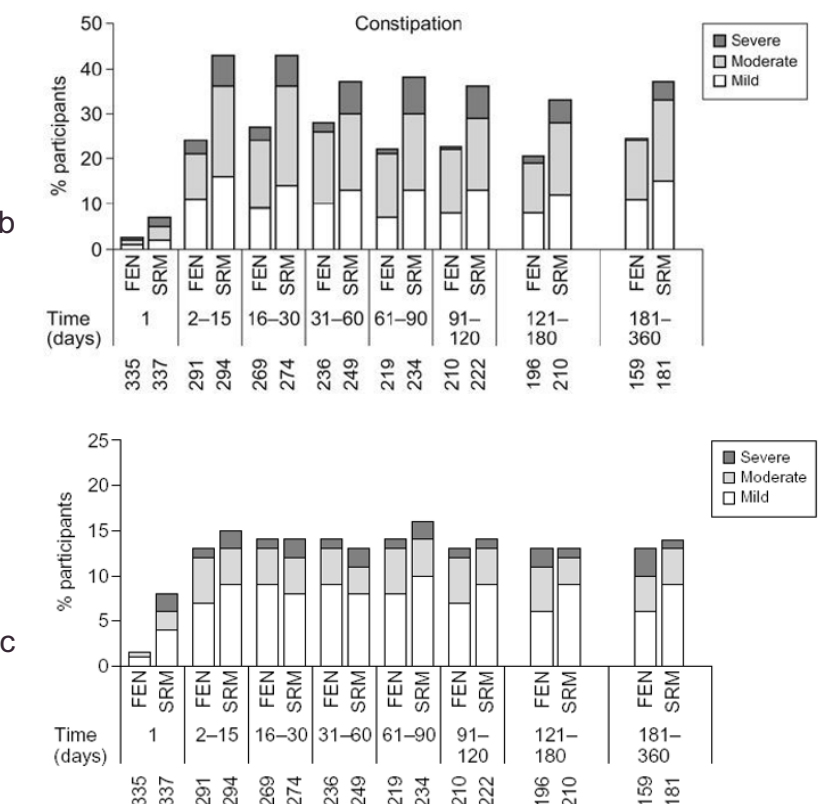

पMild
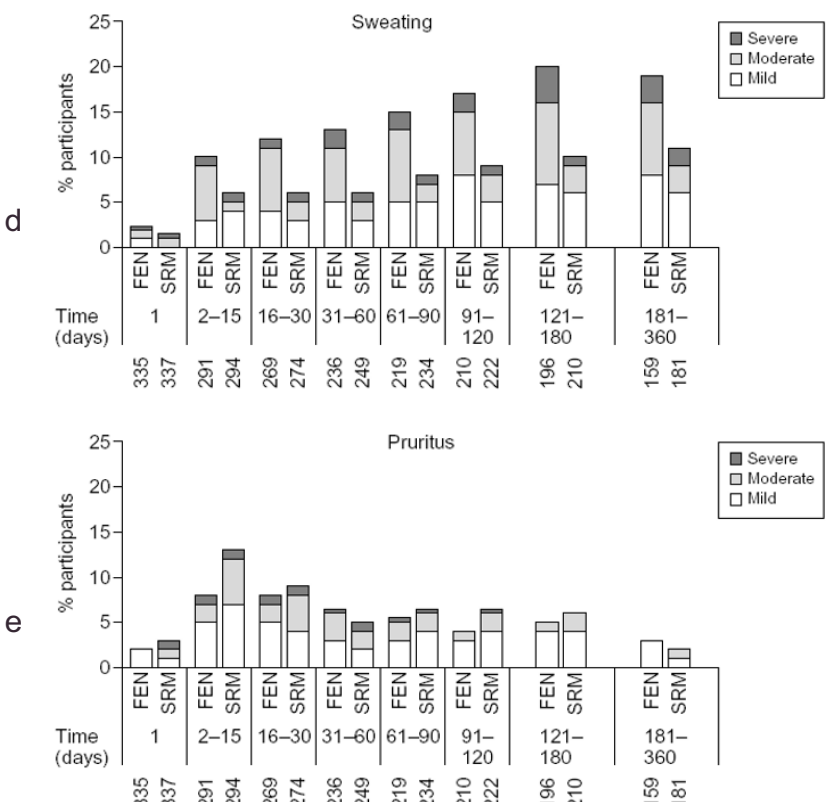

Figure 2

Incidence and severity of (a) nausea, (b) constipation, (c) somnolence, (d) sweating, and (e) pruritus. FEN, patients receiving transdermal fentanyl; SRM, patients receiving sustained release oral morphine. I, incidence at day I; 2-I5, incidences at day 2, 3, etc. Numbers below x-axis show number of patients at each time point. 
severe pain on movement fell from $66 \%$ at baseline to $21 \%$ at endpoint.

\section{Effects of age}

Older patients (defined as those at least 75 years old, $\mathrm{n}=$ $51)$ tended to use lower opioid doses than younger patients $(<75$ years, $\mathrm{n}=621)$. The median daily doses at study endpoint were $58 \mathrm{mg}$ for SRM and $43 \mu \mathrm{g} / \mathrm{h}(102$ $\mathrm{mg}$ ) for TDF for older patients compared with $116 \mathrm{mg}$ SRM and $54 \mu \mathrm{g} / \mathrm{h}(130 \mathrm{mg}) \mathrm{TDF}$ for younger patients. The average morphine dose in older patients remained stable throughout the study; the mean morphine dose was 57 $\mathrm{mg}$ at baseline and $59 \mathrm{mg}$ at endpoint, however the mean dose in patients who completed the study was $66 \mathrm{mg}$ at month 13. The average fentanyl dose was $25 \mu \mathrm{g} / \mathrm{h}$ at baseline, $44 \mu \mathrm{g} / \mathrm{h}$ at endpoint (for all patients, whenever they left the study), and $50 \mu \mathrm{g} / \mathrm{h}$ at month 13 (i.e. for patients who completed the study).

The proportion of responders tended to be higher in the younger than the older age groups (56\% vs $45 \%$, respectively, for $30 \%$ response and $40 \%$ vs $31 \%$, respectively, for $50 \%$ response). However, no statistical significance could be detected, probably due to the small sample size. The proportion of patients who withdrew because of adverse events was higher in the elderly sub-group than in the younger patients: rates of withdrawal were $56 \%(n=15)$ for SRM and $42 \%(n=10)$ for TDF in the older group compared with $29 \%(\mathrm{n}=89)$ and $37 \%(\mathrm{n}=115)$, respectively in the younger patients.

\section{Adverse events}

Most adverse events (AEs) were reported in the first few weeks of the study, except for sweating in the fentanyl group, which increased over time (Figure 3 ). To examine whether patients who experienced AEs were more likely to withdraw from the study before an effective dose had been reached, we compared doses in patients with and without the most common AEs.

The median daily opioid dose was lower for patients $<75$ years old who reported nausea than for those who did not (76 mg morphine $(\mathrm{n}=159)$ or $38 \mu \mathrm{g}$ fentanyl $(\mathrm{n}=170)$ for patients with nausea vs $85 \mathrm{mg}$ morphine $(\mathrm{n}=151)$ or $48 \mu \mathrm{g}$ fentanyl $(\mathrm{n}=141)$ for those without). This pattern was not seen for those who reported constipation (median morphine dose of SRM patients $<75$ years was 84 mg for those with ( $\mathrm{n}=204)$ vs $72 \mathrm{mg}$ for those without (n $=106)$ constipation, (doses for fentanyl $48 \mu \mathrm{g}(\mathrm{n}=163)$ vs $38 \mu \mathrm{g}(\mathrm{n}=148)$, respectively).

Evidence that vomiting may limit treatment comes from the observation that patients who experienced at least a $30 \%$ pain relief were less likely to report this $\mathrm{AE}$ than nonresponders ( $23 \%$ of responders and $33 \%$ of non-respond-

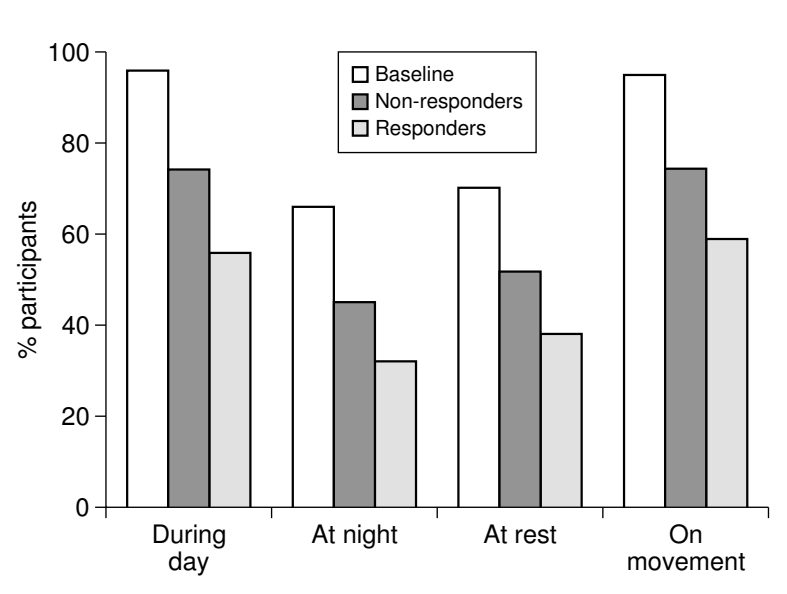

Figure 3

Proportion of patients with moderate/severe pain at baseline and endpoint by response category.

ers reported vomiting). However responders were more likely to report constipation than non-responders (67\% vs $47 \%$ ), perhaps reflecting the greater length of time they remained in the study since constipation tends to occur after several weeks of opioid treatment.

\section{Dosage and study completion}

Dose increases between 4 weeks and endpoint tended to be larger in patients who completed the study than those who dropped out. For example, the proportion of patients whose opioid dose more than doubled during this time was $24 \%$ for completers and $7 \%$ for non-completers.

\section{Best and worst responders}

Demographic and baseline characteristics of the best and worst responders (top and bottom 15\%) were compared. The mean ( \pm standard error of the mean (SEM)) duration of chronic pain was no different in the poor responders than in the best responders ( $106 \pm 10$ vs $94 \pm 8$ months).

No clear patterns emerged that might predict response, except that there were significantly more women in the SRM worst response group (73\% of the poorest responders to morphine were female compared with $49 \%$ of the poorest responders to fentanyl, $\mathrm{p}=0.017$ ).

\section{Reasons for leaving study}

Patients who left the study in the first month (i.e. early drop-outs, $\mathrm{n}=135$ comprising $20 \%$ of the total population) were compared with those who withdrew from the study at a later stage $(n=199)$. Drop-outs within the first month were more likely to be due to adverse events ( $82 \%$ vs $59 \%$ ) and less likely to be due to insufficient response ( $3 \%$ vs $15 \%$ ) than with later withdrawals. The proportion 
of patients withdrawing consent was $9 \%$ among early dropouts and $6 \%$ among later withdrawals.

Adverse events during the first month were compared between early dropouts and all patients who remained in the study for longer $(n=540)$. Nausea and vomiting were more common in early dropouts (62\% vs $43 \%$ for nausea, and $38 \%$ vs $20 \%$ for vomiting, respectively). Constipation and increased sweating were less frequent among early dropouts (36\% vs $49 \%$ for constipation, and $8 \%$ vs $14 \%$ for sweating). Pruritus was similar in early dropouts and other patients (12\% and $17 \%$, respectively).

\section{Effects of dose}

The effect of opioid dose was assessed by considering the sub-group of patients who received higher doses $(>100$ $\mu \mathrm{g} / \mathrm{h}$ TDF or $>390 \mathrm{mg} /$ day SRM, $\mathrm{n}=43$ ). The incidence of adverse events was similar in both dosage groups, except for sweating, which occurred more often in the higher dose group (35\% higher dose vs $20 \%$ lower dose, $\mathrm{p}=$ $0.0207)$. The proportion of patients achieving at least $30 \%$ pain relief was higher in the higher dose group $(70 \%$ vs $54 \%, \mathrm{p}=0.043$ ). A similar pattern was observed for the proportions achieving at least $50 \%$ pain relief, but the difference between dose groups (44\% vs 39\%) did not reach statistical significance when both treatments were considered together. There was a marked difference in the proportion of patients achieving at least $50 \%$ pain relief in the higher dose sub-group between those receiving TDF (52\% responders) and those receiving SRM (29\%). This difference was not observed in the lower dose group (39\% responders in each treatment group).

\section{Multivariate analysis}

We performed a step-wise logistic regression using 13 key variables (Table 2). No strong correlation between any covariates was found. The most influential factors for predicting a response of at least a $30 \%$ reduction of pain from baseline were employment status $\left(\chi^{2}=11.06, p=0.0259\right)$ and use of high doses of opioids $\left(\chi^{2}=3.04, \mathrm{p}=0.0811\right)$. The category 'non-professional' employment status, which included housewives but not unemployed, retired people or students, was associated with a lower likelihood of achieving a 30\% response than the 'disabled' category (odds ratio compared with disabled category 0.412 (95\% CI 0.24 to 0.70$) \mathrm{p}=0.0010$ ). The use of higher opioid doses during the trial gave an increased likelihood of achieving a 30\% response. This effect was statistically significant $(\mathrm{p}=0.049)$ in the first model, which included all covariates, but fell below statistical significance in the final model ( $\mathrm{p}=0.081$, odds ratio 1.828 (95\% CI 0.93 to 3.60)).

Variables predicting at least a 50\% reduction in pain were similar, and employment status (and the non-professional category) was one of the most influential factors, however its contribution was not statistically significant $(p=0.127)$. The strongest predictor for $50 \%$ response was the presence of neuropathic pain, which was weakly predictive of poorer response $(\mathrm{p}=0.0276)$. The odds ratio for

Table 2: Logistic regression on the probability of $30 \%$ responseNegative values indicate reduced probability of $30 \%$ response.

\begin{tabular}{|c|c|c|c|c|c|}
\hline Variable (baseline value) & Effect estimate & $\begin{array}{l}\text { p Value of Type } \\
\text { III effect }\end{array}$ & Category (p value) & Odds ratio & $95 \% \mathrm{Cl}$ \\
\hline Age & -0.0007 & 0.9350 & & 0.999 & $0.98-1.02$ \\
\hline Mental health & 0.0045 & 0.2935 & & 1.004 & $1.00-1.01$ \\
\hline Pain at rest & -0.3612 & 0.1779 & Moderatel $(0.0633)$ & 0.697 & $0.48-1.02$ \\
\hline Compared with no/slight pain & -0.2503 & & Severe $^{\mathrm{l}}(0.2783)$ & 0.779 & $0.50-1.22$ \\
\hline Pain on movement & -0.1683 & 0.6717 & Moderate $^{2}(0.6788)$ & 0.845 & $0.38-1.87$ \\
\hline Compared with no/slight pain & -0.2926 & & Severe $^{2}(0.4652)$ & 0.746 & $0.34-1.64$ \\
\hline Physical functioning (SF-36) & -0.0055 & 0.2270 & & 0.995 & $0.99-1.00$ \\
\hline Social functioning (SF-36) & -0.0036 & 0.3129 & & 0.996 & $0.99-1.00$ \\
\hline Duration of pain & -0.0006 & 0.4152 & & 0.999 & $0.99-1.00$ \\
\hline Education & -0.2680 & 0.5083 & Apprenticeship 3 (0.3462) & 0.765 & $0.44-1.34$ \\
\hline \multirow{2}{*}{$\begin{array}{l}\text { Compared with primary } \\
\text { education }\end{array}$} & 0.0649 & & Secondary education ${ }^{3}(0.7356)$ & 1.07 & $0.73-1.56$ \\
\hline & 0.2464 & & Higher education ${ }^{3}(0.4$ I 68$)$ & 1.28 & $0.71-2.32$ \\
\hline Employment & -0.1039 & 0.0582 & Employed $^{4}(0.675 \mathrm{I})$ & 0.901 & $0.55-1.47$ \\
\hline \multirow{3}{*}{$\begin{array}{l}\text { Categories compared with } \\
\text { disabled }\end{array}$} & -0.8852 & & Non-professional ${ }^{4}(0.0029)$ & 0.413 & $0.23-0.74$ \\
\hline & -0.2908 & & Retired $^{4}(0.2201)$ & 0.748 & $0.47-1.19$ \\
\hline & -0.2739 & & Student ${ }^{4}(0.4163)$ & 0.760 & $0.39-1.47$ \\
\hline High dose & 0.7185 & 0.0499 & & 2.051 & $|.00-4.2|$ \\
\hline Neuropathic pain & -0.1857 & 0.2735 & & 0.831 & $0.60-1.16$ \\
\hline Treatment group & 0.0530 & 0.7434 & & 1.054 & $0.77-1.45$ \\
\hline Sex & 0.0439 & 0.8033 & & 1.045 & $0.74-1.48$ \\
\hline
\end{tabular}


the presence of neuropathic pain on the likelihood of $50 \%$ response was 0.695 ( $95 \%$ CI 0.50 to 0.96 ).

\section{Discussion}

By 1 month, 20\% of patients had stopped treatment, and four out of five stopped treatment because of adverse events. However, $54 \%$ of patients had at least $30 \%$ pain relief during one time point of the trial and $69 \%$ of these patients were still on opioid treatment after 12 months, the dosages used by responders did not differ from those used by non-responders.

This study provided an opportunity to investigate predictive factors for response and gives important information regarding the efficacy and natural course of adverse effects over 13 months. However, this study was not originally designed to test predictors and therefore many potentially important factors were not examined (e.g. motivation and expectations of the patient and the physician, and the impact of other medications). As the study included only carefully selected patients with a long history of chronic low back pain, the findings need to be verified in a broader population.

No clear pattern of baseline pain (type or severity) or patient characteristics (e.g. age, gender) emerged that could be used to predict responders before the start of opioid treatment. However, this analysis did suggest that a 1month trial period is sufficient to determine response and tolerability in most cases. The significant relationship between response at 1 month and response after 6 and 12 months suggests that if patients have not responded to a suitable dose of strong opioid after 1 month, then treatment should be stopped and alternative pain relief introduced. However, if patients experience at least a $30 \%$ reduction in pain at 1 month, then opioid treatment should be continued, as long-term benefit is more likely. Previous studies have also found an association between response to intravenous opioids and long-term treatment [13]. As in the present study, Dellemijn et al. found that not all patients responding to a single dose of an intravenous opioid responded as well to long-term treatment. The negative predictive power was stronger, and those who did not respond to the intravenous opioid were less likely to respond to long-term transdermal treatment.

Our findings can be expressed in terms of the sensitivity and specificity of response at 1 month to predict response at 6 months. Specificity is the probability of a response at 1 month and 6 months (i.e. the true positive rate) and is calculated to be 0.505 . Sensitivity is the probability of no response at 1 month for those with no response at 6 months (i.e. the true negative rate) and is calculated to be 0.810 . Thus lack of response at 1 month has stronger neg- ative predictive power than the positive predictive power of the presence of response at 1 month.

We noted that there were significantly more women in the SRM worst response group than in the equivalent group for TDF (73\% vs $49 \%$ ). Whether this is an indicator of sex specific differences in response to opioid treatment needs further investigation.

This large dataset allowed us to examine correlations between the main outcome of the original study (pain relief expressed by a decrease in VAS pain scores) and other measurements of pain. We found a statistically significant correlation between the pain relief score and the change in back pain category (mild, moderate or severe) from baseline to study endpoint.

Gastrointestinal side effects are relatively common in patients receiving strong opioids for the first time. Nausea and vomiting appear to limit treatment in some cases, and may prevent titration to effective doses. Constipation tends to emerge after a few weeks of treatment, and occurred more frequently in patients receiving morphine than in those receiving transdermal fentanyl. The median daily opioid dose was lower in patients who reported nausea than in those who did not but this pattern was not seen for constipation. This suggests that the occurrence of nausea during the early weeks of treatment may limit dose titration, whereas constipation generally emerges later. The higher median dose of TDF in patients who reported constipation compared with those that did not might also reflect a dose-response effect, with constipation occurring only with higher doses of TDF.

The rate of adverse effect reporting is affected by the reporting method. In our study, only adverse events volunteered by patients (or observed by clinicians) were reported, whereas, in other studies, patients have been questioned specifically about the occurrence of expected side effects. This may explain why the rates of adverse events in our study are lower than those in some previous studies of strong opioids [14]. However the adverse events in this trial were analyzed with care.

Patients aged over 75 years in the SRM group showed stable doses throughout the study, in contrast to older patients receiving TDF and to the younger patients in both groups. Older patients in the SRM group reported less pain relief than younger patients; this might also suggest that effective morphine doses were not reached. One possible explanation for this is that older patients are more susceptible to dose-related morphine side effects and this limited dose escalation. This assumption is supported by the higher dropout rate in the older patient group (56\% in the TDF and $42 \%$ in the SRM group). Other studies have 
also noted that morphine side effects may be more pronounced in elderly patients [15].

Only a small proportion of patients needed high opioid doses, but these patients tended to achieve additional pain relief.

Patients who experienced effective pain relief (e.g. a decrease of at least $30 \%$ from baseline) tended to remain in the trial longer than those who did not get adequate analgesia. Some patients may have remained in the trial because of other benefits apart from the primary outcome, such as sleeping better. A few patients, who according to trial assessments had experienced no benefits, still completed the 13-month trial.

\section{Conclusion}

Strong opioid treatment can be beneficial for some patients with severe low back pain. However, there appears to be no simple method of predicting who will benefit from a strong opioid before treatment is initiated. This analysis suggests that response to a trial period of 1 month gives a good indication of who will obtain sustained benefit. Neuropathic pain does not appear to rule out response to strong opioids, but it may be associated with a poorer response. Gastrointestinal side effects are common during the first weeks of treatment, and these may limit dose titration in some patients. The best way to determine who will tolerate a strong opioid appears to be a trial period of 1 month.

\section{Competing interests}

The original study (FEN-INT-26) and the secondary analysis were funded by Janssen Pharmaceutica, the manufacturer of transdermal fentanyl. EK, KHS and RS were investigators in the original study and received funding from Janssen Pharmaceutica for this. They have also worked with Janssen on other clinical trials and received research funding and honoraria at various times. UR is an employee of Janssen Cilag.

\section{Authors' contributions}

EK and UR had the original idea for this secondary analysis. JD performed the statistical analyses. EK, KS, RS, DJ and UR all reviewed and revised several drafts of the manuscript and provided critical comments. All authors read and approved the final manuscript.

\section{Acknowledgements}

Medical writing assistance was provided by Liz Wager of Sideview on behalf of Janssen Cilag.

\section{References}

I. Allan L, Richarz U, Simpson K, Slappendel R: Transdermal fentanyl versus sustained release oral morphine in strong-opioid naive patients with chronic low back pain. Spine 2005, 30:2484-2490.
2. Farrar JT, Portenoy RK, Berlin JA, Kinman JL, Strom BL: Defining the clinically important difference in pain outcome measures. Pain 2000, 88:287-294.

3. Jellema $P$, van der Horst HE, Vlaeyen JW, Stalman WA, Bouter LM, van der Windt DA: Predictors of outcome in patients with (sub)acute low back pain differ across treatment groups. Spine 2006, 3 I: 1699-1705.

4. Enthoven P, Skargren E, Carstensen J, Oberg B: Predictive factors for I-year and 5-year outcome for disability in a working population of patients with low back pain treated in primary care. Pain 2006, I 22:137-I44.

5. Axen I, Jones J], Rosenbaum A, Lovgren PW, Halasz L, Larsen K, Leboeuf-Yde C: The Nordic Back Pain Subpopulation Program: validation and improvement of a predictive model for treatment outcome in patients with low back pain receiving chiropractic treatment. J Manip Physiol Ther 2005, 28:38I-385.

6. Leboeuf-Yde C, Gronstvedt A, Borge JA, Lothe J, Magnesen E, Nilsson O, Rosok G, Stig LC, Larsen K: The Nordic Back Pain Subpopulation Program: demographic and clinical predictors for outcome in patients receiving chiropractic treatment for persistent low back pain. J Manip Physiol Ther 2004, 27:493-502.

7. Karjalainen K, Malmivaara A, Mutanen P, Pohjolainen T, Roine R, Hurri $\mathrm{H}$ : Outcome determinants of subacute low back pain. Spine 2003, 28:2634-2640.

8. Dionne CE, Von Korff M, Koepsell TD, Deyo RA, Barlow WE, Checkoway $\mathrm{H}$ : Formal education and back pain: a review. J Epidemiol Comm Health 200I, 55:455-468.

9. Hagen KB, Holte HH, Tambs K, Bjerkedal T: Socioeconomic factors and disability retirement from back pain: a 1983-1993 population-based prospective study in Norway. Spine 2000, 25:2480-2487.

10. Kalso E, Edwards JE, Moore RA, McQuay HJ: Opioids in chronic non-cancer pain: systematic review of efficacy and safety. Pain 2004, I I 2:372-380.

II. Eisenberg E, McNicol ED, Carr DB: Efficacy and safety of opioid agonists in the treatment of neuropathic pain of nonmalignant origin: systematic review and meta-analysis of randomized controlled trials. JAMA 2005, 293:3043-3052.

12. Wasan $A D$, Davar G, Jamison R: The association between negative affect and opioid analgesia in patients with discogenic low back pain. Pain 2005, 1 1 7:245-246.

13. Dellemijn PLI, van Duijn H, Vanneste JA: Prolonged treatment with transdermal fentanyl in neuropathic pain. J Pain Symptom Man 1998, 16:220-229.

14. Heiskanen T, Kalso E: Controlled-release oxycodone and morphine in cancer related pain. Pain 1997, 73:37-45.

15. Clark AJ, Ahmedzai SH, Allan LG, Camacho F, Horbay GL, Richarz U, Simpson K: Efficacy and safety of transdermal fentanyl and sustained-release oral morphine in patients with cancer and chronic non-cancer pain. Curr Med Res Opin 2004, 20:14 19-1428.

\section{Pre-publication history}

The pre-publication history for this paper can be accessed here:

http://www.biomedcentral.com/1741-7015/5/39/prepub

Publish with Biomed Central and every scientist can read your work free of charge

"BioMed Central will be the most significant development for disseminating the results of biomedical research in our lifetime. "

Sir Paul Nurse, Cancer Research UK

Your research papers will be:

- available free of charge to the entire biomedical community

- peer reviewed and published immediately upon acceptance

- cited in PubMed and archived on PubMed Central

- yours - you keep the copyright

Submit your manuscript here:

http://www.biomedcentral.com/info/publishing_adv.asp
BioMedcentral 